\title{
Non-destructive tests on eco-friendly anti-corrosion paint
}

\author{
H. M. Hajar'1, N. Ismail ${ }^{2}$, F. Zulkifli' ${ }^{1}$, M.G.M. Sabri' ${ }^{2}$ and W. B. Wan Nik ${ }^{1 *}$ \\ ${ }^{1}$ School of Ocean Engineering, Universiti Malaysia Terengganu (UMT), \\ 21030 Kuala Terengganu, Terengganu, Malaysia, \\ ${ }^{2}$ School of Fundamental Science, Universiti Malaysia Terengganu (UMT), \\ 21030 Kuala Terengganu, Terengganu, Malaysia, Phone: +6096683342 \\ *Email: niksani@umt.edu.my
}

\begin{abstract}
Henna is identified as an excellent corrosion inhibitor and due to this reason, a research project was conducted in order to investigate the ability of henna extracts to act as an anticorrosive agent with the compatible composition for paint systems. The paint composition consisted of colophony (WW types), plasticiser (oleic acid), pigment (calcium carbonate), solvent (mixture of xylene/white spirit) and additives (zinc oxide and henna leaf extract). These ingredients were mixed until they were soluble and stirred using a high-speed disperser. In order to measure the effectiveness of the new paint system, several nondestructive tests were conducted to investigate the inhibitive properties of henna extract including measurement of substrate mass loss. The inhibition efficiency (IE) increased with the increasing amounts of inhibitor. The highest IE (\%) was $77.63 \%$ and this was produced by the paint with $8 \%$ inhibitor (P3). However, the IE value started to decrease when $12 \%$ of henna extract was incorporated into the paint matrix (P4: $58.40 \%)$. Thus, P3 acted as an optimum paint with respect to its performance on the corrosion inhibition efficiency based on mass loss measurement and electrochemical studies. Surface analyses were carried out using infrared thermography and scanning electron microscopy. These surface analysis test was carried out to support mass loss and electrochemical study. Based on the results, the performance of henna extract as a corrosion inhibitor on aluminium surface showed a great impact with the $8 \%$ of henna extract presence in the paint formulation.
\end{abstract}

Keywords: Corrosion, IR thermography, Non-destructive testing

\section{INTRODUCTION}

Metals are one of the most affected materials by the environment. This is due to the metal properties as they are easily corroded if exposed to the environment freely. Aluminium has been utilised in this work since it is the most reactive metal and has the special property of forming strong bonding to a passivating oxide film on the aluminium surface [1]. Currently, the utilisation of aluminium in industries is very vast [2] due to its properties like low specific gravity, corrosion resistance and recyclability [3-5]. Corrosion problems lead to the failure of structures such as bridges, buildings, aircrafts, automobiles and gas pipelines [6-9]. It is important to protect metallic materials to ensure long-term durability $[10,11]$. In order to ensure a long shelf life of metals, researchers have agreed that coating methods are shown to be the most effective ways to reduce these problems. The previous research on metallic structures had been focusing on anti- 
corrosion protective coatings as their surface treatment from corrosion problems [12]. The quality of coating on the surface of metals should be highly considered by calculating the ratio of corrode to the total surface area of the coating. Visual inspection by the human eye cannot put an accurate figure on rust formation, thus determining the percentage of defect area can be very difficult, even for well-trained inspectors [13]. Generally, the number of defects, as well as the size and geometry of these may influence cathodic protection effectiveness, for example, in pipeline coating [14]. In order to measure and gather corrodes information, this study focused on non-destructive techniques. The technique applied included electrochemical measurement [15], scanning electron microscopy technique and the characterisation of defects $[16,17]$ on the sample surface. In this regard, digital image processing has been applied [13] as an important technique. In addition to this technique, infrared imaging is a further powerful tool for predictive maintenance. The infrared (IR) imaging technique works by detecting the hot spots and highlights ageing areas and components that are about to fail. Application of this nondestructive technique has been widely used in various industries including engineering, food industry, agriculture, architecture, environment, medical and meteorology [18]. The advantages of applying this technique include its portability, capacity for detecting, efficiency and ability to save time [19]. Therefore, the objective of this research was to investigate the potential of henna leaves extracts as a corrosion inhibitive agent for aluminium alloy. The effectiveness of henna leave extraction as corrosion inhibitor was tested through the immersion method in seawater for 60 days and determined by mass loss and electrochemical study, while corrosion correlation and coating defect on the aluminium surface were validated by infrared thermal imaging and scanning electron microscopy.

\section{METHODS AND MATERIALS}

\section{Experimental Set Up}

The test material selected for the study was Aluminium (Al) 5083. Aluminium samples with the dimension of a square shape of $25 \mathrm{~mm} \times 25 \mathrm{~mm} \times 4 \mathrm{~mm}$ were abraded with different grades (400, 800 and 1000 grit) of emery papers and degreased with acetone. The samples were stored in desiccators before the coating process.

\section{Coating Process}

WW rosin was used as the binder and oleic acid acted as the plasticiser. The paint was prepared by mixing the binder with the plasticiser in a xylene/white spirit (solvent) mixture using a high-speed disperser. The ratio of solvent applied was $1 / 1 \%$ by weight (Table 1). The mixture was then loaded with pigments; precipitated calcium carbonate $\left(\mathrm{CaCO}_{3}\right)$ and zinc oxide $(\mathrm{ZnO})$. The mixtures were dispersed for 24 hours in order to achieve a stable state of mixture with no coagulated substances. After 24 hours, the paints were incorporated with different percentages of henna extract according to the types of paints. The incorporation of henna extract (inhibitor) into the paint matrix was $0,4,8$ and $12 \%$ of the total paint weight. The total paint thickness applied was $120 \pm 10 \mu \mathrm{m}$ by following ASTM D 6132-13. The coated specimens were allowed to dry in a vacuum oven. According to ASTM D7187-15, the coated specimens were then scratched in the way designed for measurement of paint coating tests conducted in the laboratory. 
Table 1. Paint composition expressed as \% by Wt.

\begin{tabular}{lcccc}
\hline \multirow{1}{*}{ Components } & \multicolumn{4}{c}{ Types of paint (\%) } \\
\cline { 2 - 5 } & P1 & P2 & P3 & P4 \\
\hline WW Rosin & \multicolumn{4}{c}{17.1} \\
Precipitate $\mathrm{CaCO}_{3}$ & \multicolumn{4}{c}{2.9} \\
Oleic acid & \multicolumn{4}{c}{22.0} \\
Xylene:White spirit & 43.9 & 39.9 & 35.9 & 31.9 \\
Zinc Oxide & 0 & 4 & 8 & 12 \\
Henna extract (inhibitor) & 0 & &
\end{tabular}

\section{Immersion Preparation}

Immersion preparation was done in the laboratory. The water tank was filled with seawater, approximately 10 to 11 litres. Seawater level did not affect the corrosion result, but a sufficient level was used to ensure that the samples were fully immersed in the seawater. The water tanks were labelled to differentiate the samples according to the day they were withdrawn.

\section{Mass Loss Measurement}

The samples were cleaned with acetone, rinsed with distilled water and dried in air. The initial weight $\left(W_{l}\right)$ of the specimens was determined and hung in seawater for 60 days. The corroded samples were removed, immersed in nitric acid for 2 minutes, rinsed with distilled water and dried in air. The samples were weighed again to measure the final weight $\left(W_{F}\right)$. The value of the mass loss percentage can be calculated using Eq. (1):

$$
\text { Mass Loss }(\%)=100\left(1-\frac{\mathrm{W}_{\mathrm{I}}}{\mathrm{W}_{\mathrm{F}}}\right)
$$

While corrosion rate and inhibition efficiency (IE) of inhibitor were calculated using Eq. (2) and (3), respectively:

$$
C R=\frac{\text { Mass loss }(g)}{\operatorname{area~}\left(m^{2}\right) \times \text { time }(\text { day })}
$$

While inhibition efficiency (IE) was calculated using Eq. (3):

$$
I E(\%)=\frac{C R_{O}-C R_{i}}{C R_{O}} X 100
$$

where $C R_{O}$ and $C R_{i}$ are the corrosion rate in the absence and presence of various percentages of inhibitor, respectively.

\section{Electrochemical Study}

Electrochemical measurements performed an impedance technique for corrosion of aluminium and evaluation of coatings on metal substrates. Three conventional electrodes and $150 \mathrm{~mL}$ seawater that acted as electrolyte were tested at room temperature. The three electrodes consisted of a counter electrode (glassy carbon electrode), a reference electrode (Ag/AgCl electrode) and a working electrode (specimen, Coated AA 5083). This study was conducted using AUTOLAB PGSTAT302N controlled by NOVA software. 


\section{Infrared Thermography Technique}

For this study, a thermal imaging technique was applied to detect coating defects on the surface of the coated aluminium after exposure to the seawater for 60 days. The IR camera used was an IR Flir camera and an active thermal imaging approach was applied in order to investigate the defects present on the coated aluminium. The coated aluminium samples were heated in an oven at $100^{\circ} \mathrm{C}$ for an hour [20] before active thermography was applied. After an hour, thermal images were recorded at a room temperature of $29{ }^{\circ} \mathrm{C}$.

\section{Scanning Electron Microscopy}

The effect of the inhibitor on corrosion process of the Aluminium 5083 surface was evaluated using a scanning electron microscope (SEM). The images were recorded using JSM-6390 LA scanning electron. The samples of P1, P2, P3 and P4 were examined at the magnification of X50 $500 \mu \mathrm{m}$.

\section{RESULTS AND DISCUSSION}

\section{Mass Loss Measurement}

Figure 1 shows the percentage of mass loss for P1, P2, P3 and P4 after 60 days of immersion in seawater. $\mathrm{P} 1$ recorded the highest percentage of mass loss with the reading of $0.14 \%$, followed by P2 with mass loss (\%) of $0.10 \%$, P4 with mass loss of $0.07 \%$ and the smallest value of mass loss (\%) was $0.05 \%$ for $\mathrm{P} 3$.

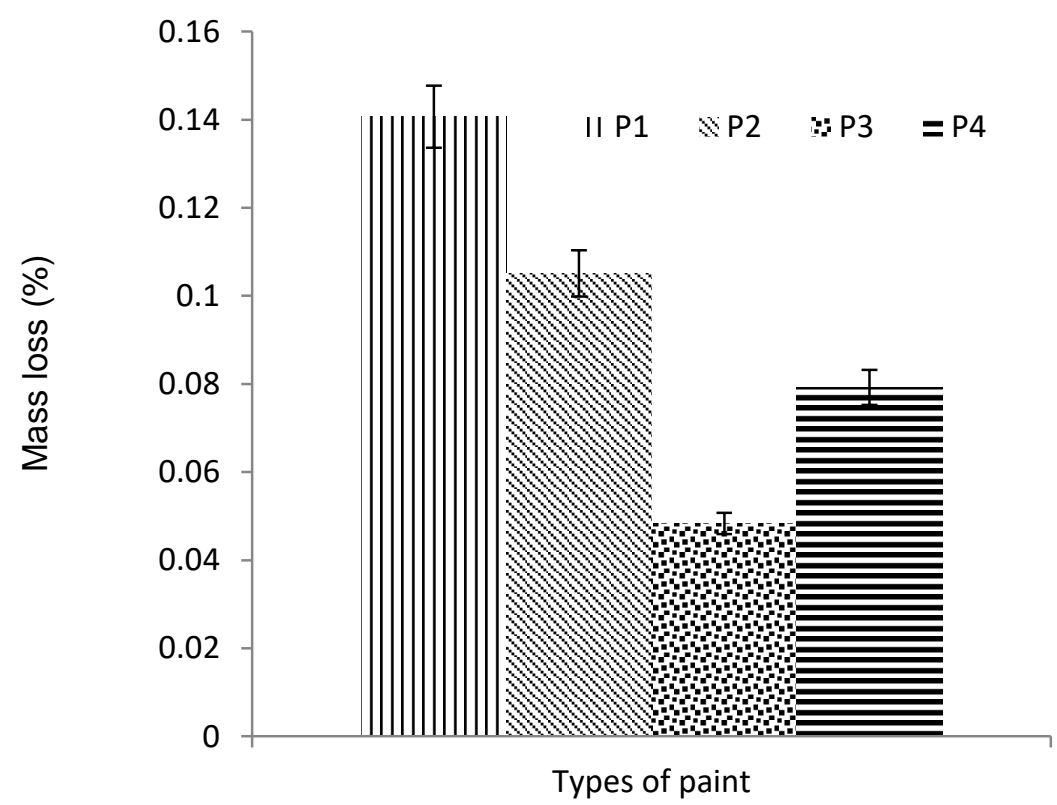

Figure 1. Mass loss percentage versus types of paint after 60 days of immersion.

Mass loss result can be correlated to the corrosion rate and IE (\%) measurement. The reading of corrosion rate and IE (\%) for every type of paint are given in Table 2 . The effectiveness of the extracts in reducing the corrosion rate of Al 5083 was estimated in terms of inhibition efficiency. The results indicated that the inhibition efficiency of henna extract increased with the increasing percentage of henna extract up to $8 \%$ for P3. However, the percentage of inhibition efficiency decreased when the percentage of henna extract was further increased up to $12 \%(\mathrm{P} 4)$. This occurred due to the limitation of the absorption of henna extract towards substrate, since the inhibitor adsorption on the active 
sites of steel surface was liable for the hindrance from aggressive species access to metal surface [21]. According to Alam et al., (2007)[22], increasing the henna extract concentration decreased the absorption performance and it clearly can be explained that the absolute quantity diminished with the increasing henna concentration. The value of corrosion rate decreased with the increased value of inhibition efficiency for 60 days of immersion. The presence of henna extract in the coating system led to the decrease in the value of corrosion rate [23].

Table 2. Corrosion parameters obtained from mass loss measurement of coated aluminium immersed in seawater after 60 days of immersion.

\begin{tabular}{cccc}
\hline Types of paint & Mass Loss $(\mathrm{g})$ & $C R(\mathrm{~mm} / \mathrm{yr})$ & $I E(\%)$ \\
\hline P1 & 0.1173 & 0.021461 & - \\
P2 & 0.0802 & 0.014673 & 31.63 \\
P3 & 0.0261 & 0.004775 & 77.63 \\
P4 & 0.0488 & 0.008928 & 58.40 \\
\hline
\end{tabular}

\section{Electrochemical study}

The measurements of electrochemical impedance are presented in the form of a Nyquist plot (Figure 2). From Figure 2, the curves are shown as capacitive semi-circles. The features of all the impedance spectra exhibit a similar shape. It can be seen that P1 has the smallest semi-circle, followed by $\mathrm{P} 2$ and $\mathrm{P} 4$. The largest semi-circle is represented by P3. A larger semi-circle indicates a better degree of resistance [24].

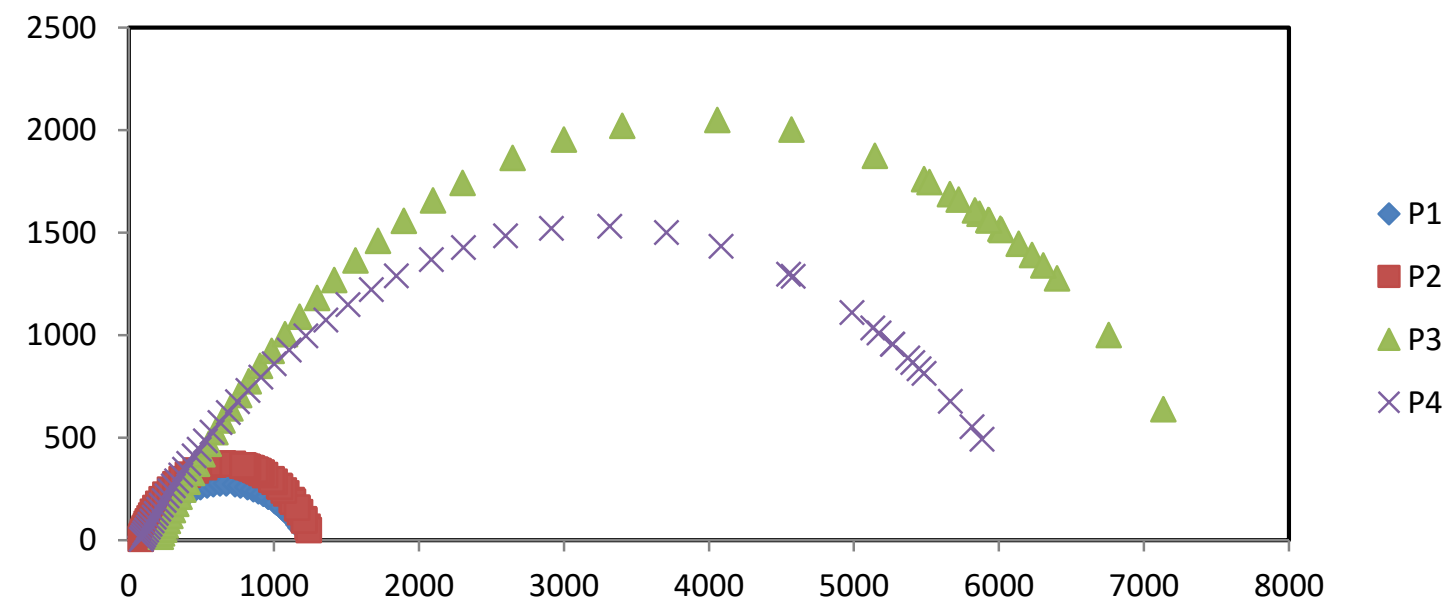

Figure 2. Nyquist plot of specimen immersed in 12 days of seawater.

Double layer capacitance $\left(C_{d l}\right)$ value started to increase from $2.47^{-5} \mathrm{~F}$ for $\mathrm{P} 1$ and $72.2^{-5} \mathrm{~F}$ for $\mathrm{P} 2$. However, the $C_{d l}$ value decreased to $3.22^{-5} \mathrm{~F}$ for $\mathrm{P} 3$, and started to increase for P4 with the $C_{d l}$ reading of $5.98^{-5} \mathrm{~F}$. Due to the decrease of the $C_{d l}$ values, it showed that the absorption of inhibitor took place on the metal surface in seawater. Besides this, the other parameter that needed to be measured was potential resistance $\left(R_{p}\right)$. The value of $R_{p}$ increased as the percentage of inhibitor increased. The $R_{p}$ value increased from $1173.5 \mathrm{k} \Omega, 1188.9 \mathrm{k} \Omega$ and $7411.7 \mathrm{k} \Omega$, respectively, for P1, P2 and P3. However, the $R_{p}$ value decreased for $\mathrm{P} 4$ (in which the henna percentage was $12 \%$ ) to the value of 6252.8 
$\mathrm{k} \Omega$. The formation of a deposited layer on the substrate led to the production of a high impedance value of the coating and slowed down the rate of electrolyte penetration into the coating [25].

\section{Thermography Analysis}

Figure 3 shows thermography of coated aluminium with different percentages of henna extract. The identified defects area was caused by the presence small holes during the immersion process. The scratched area produced a red colour contour which was a sign of the defect area. The scratched areas for P1 and P2 showed a similar colour contour where $\mathrm{P} 1$ indicated the hottest spot (red) with the temperature recorded at $71.0^{\circ} \mathrm{C}$ and this was followed by $\mathrm{P} 2$ with a temperature of $68.2^{\circ} \mathrm{C}$. Furthermore, the results for P3 and P4 produced lower colour contour indexes (yellow) with the temperatures recorded being $63.5^{\circ} \mathrm{C}$ and $66.3^{\circ} \mathrm{C}$, respectively. However, P3 showed only a small area detected as a defect area on the scratched part with no other small holes or voids on the coated aluminium surface. Even though P4 had a low colour contour index, the area detected was larger than P3 at the scratched area. The upper side of the P4 sample also showed an affected area due to the corrosion. This result is consistent with the earlier findings for the metal or objects that were about to fail since the hot spot was detected with a high index of colour contour [18].

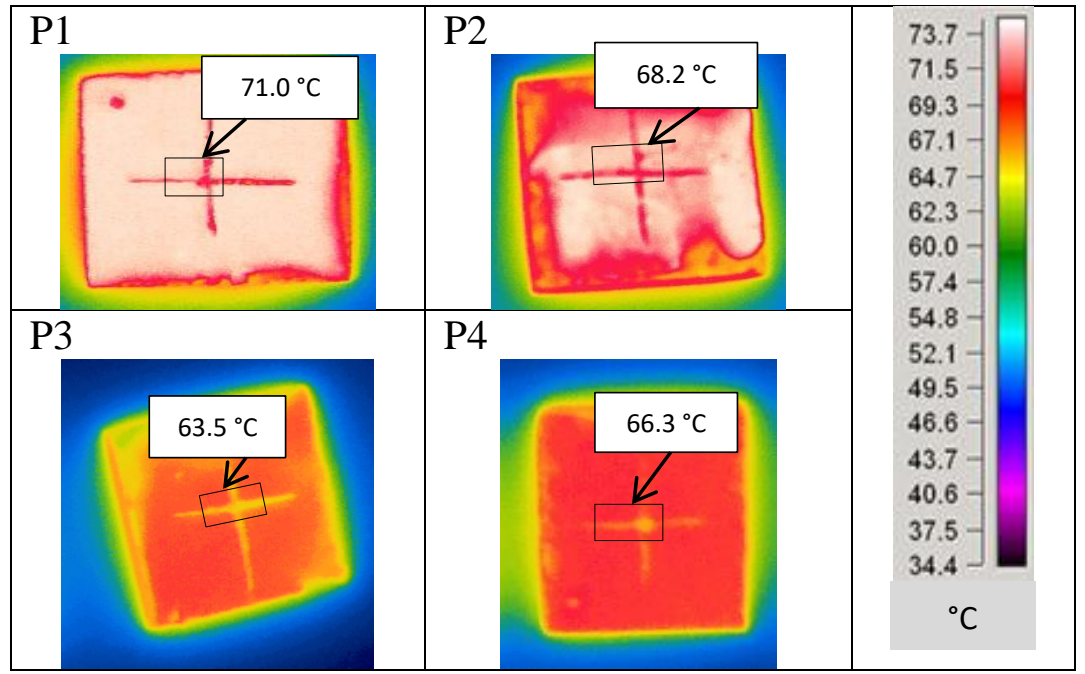

Figure 3. Thermography analysis of coated aluminium with different percentages of henna extract.

\section{Scanning Electron Microscope}

SEM micrographs of the coated aluminium of P1, P2, P3 and P4 are shown in Figure 4. Based on Figure 4, the amount of filler applied into the coating system affected the dispersed phase and finally the mechanical properties [26]. The micrograph revealed that the absence of henna extract ( $\mathrm{P} 1)$ produced a large pitting on the sample since there was a line of cracking on the coating. In the presence of $4 \%$ henna extract (P2) in the coating system, the size of the pitting was reduced. However, the line of cracking still appeared. According to the SEM micrographs, P3 showed an excellent performance and also the best out of all the other types of paint; it had a smooth surface that was crack-free. In addition, the presence of the optimum inhibitor percentage in this sample reduced surface damage and resulted in a smooth surface [27, 28]. Due to the limitation of the absorption 
of henna extract towards the substrate, a small crack and damage on the surface of the P4 sample appeared. Another factor may be due to the inhomogeneity of coating mixture.

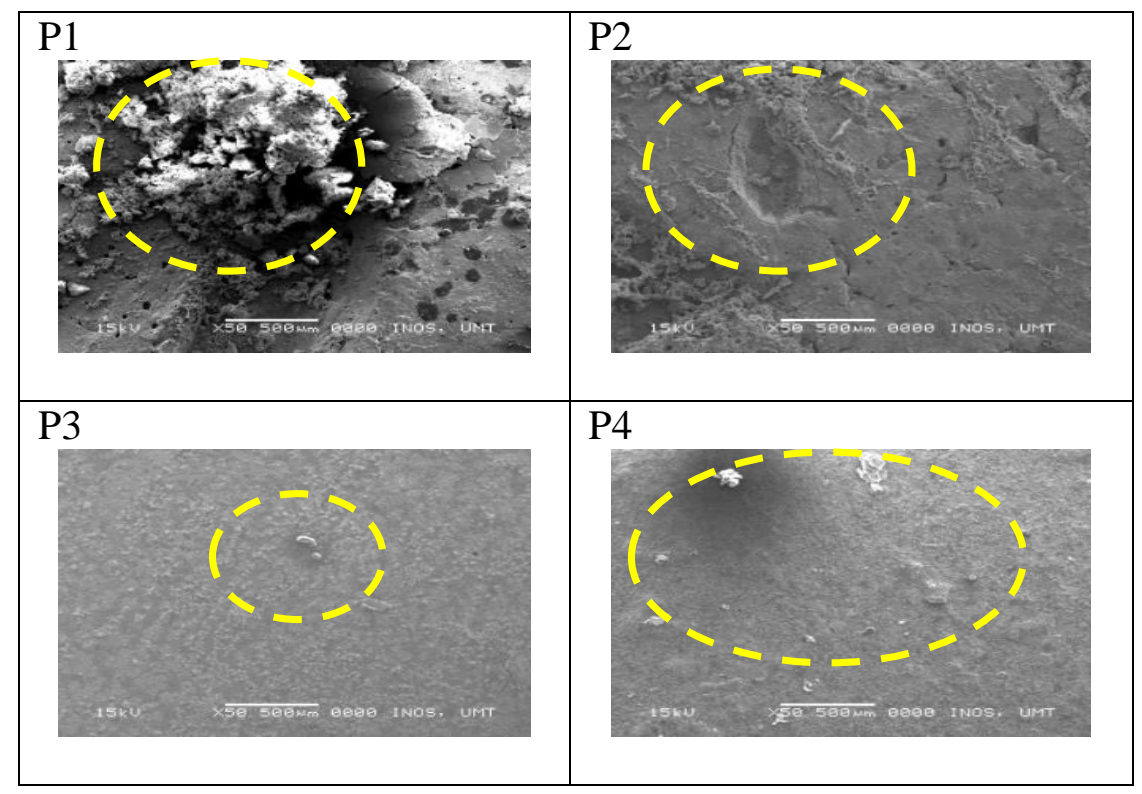

Figure 4. SEM micrographs of paints P1, P2, P3 and P4 after immersion in seawater for 60 days.

\section{CONCLUSIONS}

The inhibition effect of henna extract on the aluminium was investigated through various methods. The corrosion rate after 60 days immersion of aluminium coated with P3 showed the lowest value $(0.004775 \mathrm{~mm} / \mathrm{yr})$ due to the right range of inhibitor presence in a coating system. Other than that, the highest inhibition efficiency recorded was $77.63 \%$ as observed in P3, while IR thermography and SEM analysis have confirmed that there were damage and coating defects detected on the coated aluminium substrate. The presence of the right range of henna extract $(8 \%)$ has reduced coating irregularities and also minimised coating defect. Thus, it is a sign of a good coating system when $8 \%$ of henna extract is present in the paint formulation.

\section{ACKNOWLEDGEMENTS}

The author greatly acknowledges the Research fund Look East Policy 2.0, Vot. No.53168 for contributing fund to this study. Also, the author would like to thank collaborator form Universiti Malaysia Pahang (UMP), Prof. Ir. Dr. Kamarul Hawari Ghazali for granting with the use of FLIR thermography camera.

\section{REFERENCES}

[1] Krishnaveni K, K. R. Effect of aqueous extract of leaves of Morinda tinctoria on corrosion inhibition of aluminium surface in $\mathrm{HCl}$ medium. Transactions of Nonferrous Metals Society of China. 2014;24:2704-12.

[2] Rao VR, Ramanaiah N, Rao MS, Sarcar MM, G. K. Optimisation of process parameters for minimum volumetric wear rate on AA7075-TiC metal matrix 
composite. International Journal of Automotive \& Mechanical Engineering. 2016;13:3669-80.

[3] Ishak M, Noordin NF, Razali AS, Shah LH, FR. R. Effect of filler on weld metal structure of AA6061 aluminum alloy by tungsten inert gas welding. International Journal of Automotive and Mechanical Engineering. 2015;11:2438-46.

[4] Zakaria KA, Suhadak FHA, Ali MB, Abdullah S, Ghazali MJ. Influence of mechanical properties on load sequence effect and fatigue life of aluminium alloy. Journal of Mechanical Engineering and Sciences. 2017;14:2469-77.

[5] Khan MM, Dixit G. Erosive wear response of SiCp reinforced aluminium based metal matrix composite: Effects of test environments. Journal of Mechanical Engineering and Sciences. 2017;14:2401-14.

[6] Sørensen PA, Kiil S, Dam-Johansen K, CE. W. Anticorrosive coatings: a review. Journal of Coatings Technology and Research. 2009;6:135-76.

[7] Shah HN. Structural and mechanical characterisation of the chromium nitride hard coating deposited on the silicon and glass substrate. International Journal of Automotive and Mechanical Engineering. 2017;14:3872-86.

[8] Islami N, Rashid S, Ariffin AK, Nuawi MZ. Stress corrosion damage on austenitic stainless steel in sodium chloride. International Journal of Automotive and Mechanical Engineering. 2017;14:3824-36.

[9] Haque MM, Alam Limon S, Moniruzzaman M, Bepari MMA. Corrosion comparison of galvanized steel and aluminum in aqueous environments. International Journal of Automotive and Mechanical Engineering. 2014;9:175867.

[10] Plawecka M, Snihirova D, Martins B, Szczepanowicz K, Warszynski P, MF. M. Self healing ability of inhibitor-containing nanocapsules loaded in epoxy coatings applied on aluminium 5083 and galvanneal substrates. Electrochimica Acta. 2014;140:282-93.

[11] Abu Bakar A, Mohd Ali MKF, Md Noor N, Yahaya N, Ismail M, Abdullah A. Bio-corrosion of carbon steel by sulfate reducing bacteria consortium in oil and gas pipelines. Journal of Mechanical Engineering and Sciences. 2017;11:2592600.

[12] Yabuki A. Particle-induced damage and subsequent healing of materials: Erosion, corrosion and self-healing coatings. Advanced Powder Technology. 2011;22:30310.

[13] Shen HK, Chen PH, LM. C. Automated steel bridge coating rust defect recognition method based on color and texture feature. Automation in Construction. 2013;31:338-56.

[14] Dong CF, Fu AQ, Li XG, Cheng Y. Localized EIS characterization of corrosion of steel at coating defect under cathodic protection. Electrochimica Acta. 2008;54:628-33.

[15] Islami N, Rashid S, Ariffin AK, MZ. N. Stress corrosion damage on austenitic stainless steel in sodium chloride. International Journal of Automotive \& Mechanical Engineering. 2017;14:3824-36.

[16] Rossignol J, Plassard C, Bourillot E, Calonne O, Foucault M, E. L. Nondestructive technique to detect local buried defects in metal sample by scanning microwave microscopy. Sensors and Actuators A: Physical. 2012;186:219-22.

[17] Yusof MFM, Kamaruzaman MA, Zubair M, M. I. Detection of defects on weld bead through the wavelet analysis of the acquired arc sound signal. Journal of Mechanical Engineering and Sciences. 2016;10:2031-42. 
[18] Suriani MJ, Ali A, Khalina A, Sapuan SM, S. A. Detection of defects in kenaf/epoxy using infrared thermal imaging technique. Procedia Chemistry. 2012;4:172-8.

[19] Rodriguez-Martin M, Lagüela S, González-Aguilera D, J. M. Thermographic test for the geometric characterization of cracks in welding using IR image rectification. Automation in Construction. 2016;61:58-65.

[20] Maldague X. Theory and practice of infrared technology for nondestructive testing. Maldague X: John Wiley; 2001.

[21] Jokar M, Farahani TS, B. R. Electrochemical and surface characterizations of morus alba pendula leaves extract (MAPLE) as a green corrosion inhibitor for steel in $1 \mathrm{M} \mathrm{HCl}$. Journal of the Taiwan Institute of Chemical Engineers. 2016;63:436-52.

[22] Alam MM, Rahman ML, MZ. H. Extraction of henna leaf dye and its dyeing effects on textile fibre. Bangladesh Journal of Scientific and Industrial Research. 2007;42:217-22.

[23] Huang D, Hu J, Song GL, X. G. Inhibition effect of inorganic and organic inhibitors on the corrosion of $\mathrm{Mg}-10 \mathrm{Gd}-3 \mathrm{Y}-0.5 \mathrm{Zr}$ alloy in an ethylene glycol solution at ambient and elevated temperatures. Electrochimica Acta. 2011;56:10166-78.

[24] Gapsari F, Soenoko R, Suprapto A, W. S. Bee wax propolis extract as eco-friendly corrosion inhibitors for 304SS in sulfuric acid. International Journal of Corrosion. 2015;2015:1-10.

[25] Al-Borno A, Chen X, S. KD. Effect of high temperature sodium hydroxide immersion on fusion bond epoxy coating. International Journal of Corrosion. 2015;2015:1-7.

[26] Norazlina H, Fahmi ARM, WM. H. CaCO3 from seashells as a reinforcing filler for natural rubber. Journal of Mechanical Engineering and Sciences.8:1481-8.

[27] Hamdy A, NS. E-G. Thermodynamic, adsorption and electrochemical studies for corrosion inhibition of carbon steel by henna extract in acid medium. Egyptian Journal of Petroleum. 2013;22:17-25.

[28] Ituen E. Akaranta O, James A, S. S. Green and sustainable local biomaterials for oilfield chemicals: Griffonia simplicifolia extract as steel corrosion inhibitor in hydrochloric acid. Sustainable Materials and Technologies. 2017;11:12-8. 